\title{
EDITORIAL
}

\section{Continuous Education in Respiratory Medicine: European Respiratory Monographs}

\author{
L.M. Fabbri*
}

\begin{abstract}
As part of the activities of the European School of Respiratory Medicine, it was decided to develop a series of clinical monographs to be distributed to all members and subscribers of the European Respiratory Journal, and also available for sale. One or two expert editors are appointed for each monograph, with the responsibility of suggesting the titles and authors of individual chapters and of reviewing and editing the final monograph. The topics of the monographs are strictly clinical, selected on the basis of the need for review of rapidly evolving areas of respiratory medicine. The title of the series is "European Respiratory Monographs", to reflect their main aim, i.e. continuous education of practising
\end{abstract}

*Correspondence address: L.M. Fabbri, Sezione de Fisiopathologia Respiratoria, Via L Borsari 46, 44100 Ferrara, Italy pneumonologists and physicians. The programme starts in 1995 with three monographs, the first on "Lung Cancer", the second on "AIDS and the Lung", the third on "Asthma". The first was distributed with the October issue of the European Respiratory Journal. The second will follow with the December issue.

The main aim of the monograph is to offer readers a sort of consensus on clinically relevant issues, and to give them the opportunity to find in the monograph guidelines for diagnosis and treatment. I believe that the contributors to the monographs have achieved these goals.

We plan to publish a nationally edited version of the same monographs, which will include translation of the original articles plus, when appropriate, one or more articles providing a national perspective. 